\title{
Assessment of the impact on human health of industrial emissions to air: Does the result depend on the applied method?
}

\author{
J. Van Caneghem ${ }^{a^{*}}$, C. Block ${ }^{\mathrm{b}}$, C. Vandecasteele ${ }^{\mathrm{a}}$
}

a'Department of Chemical Engineering, Leuven University, W. Decroylaan 46, B3001 Leuven, Belgium

${ }^{\mathrm{b}}$ Groep T Leuven Engineering College, Vesaliusstraat 16, B-3000 Leuven, Belgium

Keywords: Impact assessment; Human health; Industry; Characterization factor

\begin{abstract}
The impact on human health of substances emitted to air by the Flemish industry was calculated with characterization factors (CFs) provided by the CML, Eco-indicator 99, EPS, EDIP and USEtox impact assessment methods. A comparison of the results pointed out that the choice of the CFs can greatly influence conclusions on the trend of the impact over time and on the relative contribution of the individual substances. If the impact on human health of organic substances and heavy metals was assessed separately, the differences between methods were less pronounced. In this case, the impacts on human health obtained by simply dividing the emitted masses of substances by the respective minimal risk concentrations or minimal risk doses, were comparable to those calculated with the CFs of the model-based methods.
\end{abstract}

\footnotetext{
* Corresponding author. Tel.: ++32 16322353, fax: ++3216322991. E-mail address: jo.vancaneghem@cit.kuleuven.be
} 


\section{Introduction}

Industrial production processes often emit substances to air that have a negative impact on human health. Over the last two decades, methods have become available for the quantification of these impacts, mostly in the framework of life cycle impact assessment (LCIA). In general, the estimated impact on human health of a substance is estimated by multiplying the emitted mass of this substance with a characterization factor (CF). The total impact on human health of all the substances emitted by an industrial production process then equals the sum of the impacts of the individual substances. The aggregation of impacts of substances emitted by industrial production processes and regions is also applied in eco-efficiency evaluation [1], [2].

An analysis $[3,4]$ of commonly used impact assessment methodologies such as the CML- [5,6,7,8], Eco-indicator 99- [9], EPS- [10] and EDIP-method [11], showed that the assessment of impacts on human health is not as straightforward as the assessment of environmental impacts in the impact categories global warming, ozone depletion, acidification, photochemical ozone formation or eutrophication, for which more consensus exists. Although most assessment methods make in principle use of similar models for the derivation of CFs, typically including analysis of environmental distribution or fate, of resulting human exposure and of effect, different model settings (e.g. wind speed, rain or no-rain conditions, possible concentration gradients in soil) and value choices (e.g. inclusion of dermal exposure, aggregation of effects in one score) are made for each method. Also the substance specific input parameters, such as octanol-water partition coefficients, vapor pressures etc. vary from method to method. These differences in model and parameter settings between methods may 
lead to extremely large differences in CFs (up to 13 orders of magnitude according to Rosenbaum et al. [12]), which is confusing from a practitioner's point of view because the same emission inventory may result in considerable different impacts depending on the applied assessment method.

The first aim of this paper is to compare the results of the human health impact assessment of regular industrial process emissions using the CML-, Eco-indicator 99, EPS and EDIP-CFs. For a thorough evaluation of the differences in models, settings and value choices, reference is made to Bare and Gloria [4] and Hertwich [13]. In 2005, the United Nations Environmental Program (UNEP) and the Society for Environmental Toxicology and Chemistry (SETAC) initiated a comprehensive comparison of human toxicity and freshwater ecotoxicity characterization models, which resulted in the development of a scientific consensus model, called USEtox $[12,14]$. In a second part of this paper, the CFs for human health derived by means of the consensus model are applied to the same industrial emission data as before and the results are compared.

It was also recognized by Bare and Gloria [4] that the true details about the models and methodologies used to derive CFs may be difficult to understand without a thorough study of the documents describing the scientific background of the methods. Therefore, this paper also compares the impacts obtained by simply dividing the emitted masses of substances by the respective Minimal Risk Concentration (MRC $\left.{ }^{1}\right)$

\footnotetext{
${ }^{1} \mathrm{MRC}$ or minimal risk concentration is the concentration in the air, expressed in $\mathrm{mg} / \mathrm{m}^{3}$, which can be inhaled over a lifetime by humans without adverse non cancer health effects
} 
or Minimal Risk Dose $\left(\mathrm{MRD}^{2}\right)$ with the impacts calculated by means of the (model based) CML-, Eco-indicator 99-, EPS-, EDIP- and USEtox-CFs.

\section{Methods}

As it is not the aim of this paper to discuss the differences between the models used to derive the characterization factors ${ }^{3}$ in the considered assessment methods, sections $2.1-2.5$ only briefly describe the model settings and value choices made within each method. In each of these sections, reference is made to the literature discussing the scientific background in more detail. Table 1 summarizes the most important differences between the methods.

\footnotetext{
${ }^{2} \mathrm{MRD}$ or minimal risk dose is the estimate of the amount of a substance, expressed in $\mathrm{mg} / \mathrm{kg}$ body weight.day, which can be ingested daily over a lifetime by humans without adverse non cancer health effects.

${ }^{3}$ Each assessment method uses its own terminology to indicate the factors used for the calculation of impacts or damages to human health from emissions. For the sake of clarity, the expression "characterization factor" is used to indicate these factors for each method.
} 
Table 1: Overview of the most important differences between the considered assessment methods

\begin{tabular}{|c|c|c|c|c|}
\hline Method & Model used & Considered effects & Mid-/Endpoint & $\begin{array}{l}\text { CF Uncertainty } \\
\text { factor }\end{array}$ \\
\hline CML & USES-LCA & Cancer, non-cancer & $\begin{array}{l}\text { Midpoint: estimated } \\
\text { exposure divided by } \\
\text { human limit value }\end{array}$ & $1.7 \times 10^{1}-1.7 \times 10^{3} \mathrm{a}$ \\
\hline Eco-Indicator 99 & EUSES & $\begin{array}{l}\text { Cancer, non-cancer, } \\
\text { psychological }\end{array}$ & $\begin{array}{l}\text { Endpoint: effects } \\
\text { are linked to } \\
\text { damages to human } \\
\text { health }\end{array}$ & $\begin{array}{l}4-1.6 \times 10^{3 a} \\
\text { ( } 3 \text { perspectives) }\end{array}$ \\
\hline EPS & Empirical data & Cancer, non-cancer, & $\begin{array}{l}\text { Endpoint: effects } \\
\text { are linked to } \\
\text { damages expressed } \\
\text { in EUR }\end{array}$ & $2.3 \times 10^{1}-1.0 \times 10^{4 a}$ \\
\hline EDIP & Key parameters & Cancer, non-cancer & $\begin{array}{l}\text { Midpoint: estimated } \\
\text { exposure divided by } \\
\text { human limit value }\end{array}$ & Not quantified \\
\hline USEtox & $\begin{array}{l}\text { Consensus fate- } \\
\text { exposure-effect } \\
\text { model }\end{array}$ & Cancer, non-cancer & $\begin{array}{l}\text { Endpoint: effects } \\
\text { are linked to } \\
\text { number of desease } \\
\text { cases }\end{array}$ & $100-1000$ \\
\hline MRC/MRD & Non & Non-cancer & $\begin{array}{l}\text { Differences in fate } \\
\text { and exposure not } \\
\text { considered }\end{array}$ & Not quantified \\
\hline
\end{tabular}

${ }^{\text {a }}$ defined as the ratio of the $97.5^{\text {th }}$ and $2.5^{\text {th }}$ percentile value for a lognormal distribution of the

CFs. As the uncertainty factor is substance specific, the range reported by the method developers is given. 
Table 2: Emission inventory for the Flemish industry (2000-2007)

\begin{tabular}{|c|c|c|c|c|c|c|c|c|}
\hline Emissions (kg/year) & 2000 & 2001 & 2002 & 2003 & 2004 & 2005 & 2006 & 2007 \\
\hline \multicolumn{9}{|c|}{ Organic substances (Volatile Organic } \\
\hline Benzene & $1,240,151$ & $1,093,715$ & 958,510 & 838,817 & 806,095 & 638.987 & 553,772 & 480,067 \\
\hline Formaldehyde & 886,038 & 819,521 & 753,364 & 735,780 & 640,606 & 560,858 & 501,201 & 474,235 \\
\hline PAHs (total) & 178,222 & 187,088 & 181,334 & 198,210 & 194,426 & 200,930 & 188,368 & 188,011 \\
\hline Toluene & $4,248,146$ & $4,269,339$ & $3,496,409$ & $2,791,390$ & $2,577,089$ & $2,098,471$ & $1,877,023$ & $1,383,524$ \\
\hline Xylene-isomers & $4,472,220$ & $4,530,890$ & $3,848,812$ & $3,568,213$ & $2,757,255$ & $2,304,885$ & $2,077,272$ & $2,091,200$ \\
\hline \multicolumn{9}{|l|}{$\overline{\text { Chlorinated organic substances }}$} \\
\hline 1,2-dichloroethane & 15,752 & 26,630 & 37,563 & 40,372 & 27,623 & 79,841 & 76,001 & 33,828 \\
\hline $2,3,7,8$-TCDD & 0.058 & 0.056 & 0.043 & 0.043 & 0.043 & 0.047 & 0.043 & 0.041 \\
\hline Tetrachloroethene & 25,274 & 32,160 & 26,565 & 21,140 & 13,351 & 8,623 & 8,112 & 9,169 \\
\hline Vinylchloride & 8,014 & 6,094 & 7,810 & 4,992 & 11,064 & 9,000 & 8,226 & 5,512 \\
\hline $\begin{array}{l}\mathrm{CO}_{2}+\text { other greenhouse gases } \\
(\mathrm{GHGs})^{\mathrm{a}} \\
\text { Ozone depleting substances }^{\mathrm{b}}\end{array}$ & $\begin{array}{c}22,544,911,672 \\
608,351\end{array}$ & $\begin{array}{c}21,827,516,015 \\
529,014\end{array}$ & $\begin{array}{c}21,735,040,237 \\
451,638\end{array}$ & $\begin{array}{c}21,561,904,627 \\
415,166\end{array}$ & $\begin{array}{c}22,092,853,327 \\
346,398\end{array}$ & $\begin{array}{c}21,745,649,456 \\
249,331\end{array}$ & $\begin{array}{c}20,314,570,479 \\
193,609\end{array}$ & $\begin{array}{c}18,623,586,477 \\
-\end{array}$ \\
\hline \multicolumn{9}{|l|}{ Inorganic substances } \\
\hline Carbon disulphide & $1,900,738$ & $1,995,248$ & $1,355,403$ & $1,496,365$ & $1,467,510$ & $1,060,245$ & 984,725 & 921,512 \\
\hline $\mathrm{CO}$ & $384,458,745$ & $316,141,636$ & $346,906,678$ & $322,246,755$ & $344,899,150$ & $329,737,389$ & $321,995,467$ & $277,107,688$ \\
\hline Dust (PM10) & $23,132,095$ & $21,804,513$ & $21,815,824$ & $22,165,748$ & $22,118,817$ & $19,697,193$ & $19,249,229$ & $17,916,253$ \\
\hline $\mathrm{NH}_{3}$ & $63,853,451$ & $60,327,823$ & $58,254,320$ & $55,617,352$ & $48,751,108$ & $47,169,874$ & $46,286,763$ & $43,909,190$ \\
\hline $\mathrm{NO}_{\mathrm{x}}$ & $205,804,783$ & $198,297,898$ & $188,319,023$ & $187,025,332$ & $186,626,193$ & $182,130,188$ & $171,247,466$ & $163,028,705$ \\
\hline $\mathrm{SO}_{\mathrm{X}}$ as $\mathrm{SO}_{2}$ & $117,063,790$ & $113,917,186$ & $105,228,129$ & $102,455,647$ & $110,230,931$ & $99,614,988$ & $94,553,819$ & $89,042,130$ \\
\hline
\end{tabular}




\section{Heavy metals}

\begin{tabular}{|c|c|c|c|c|c|c|c|c|}
\hline As & 1,685 & 1,856 & 1,601 & 1,363 & 1,428 & 1,519 & 1,483 & 1,770 \\
\hline $\mathrm{Be}$ & 89 & 69 & 57 & 62 & 70 & 65 & 81 & 52 \\
\hline $\mathrm{Cd}$ & 777 & 614 & 774 & 689 & 1,006 & 736 & 733 & 510 \\
\hline Co & 1,023 & 1,099 & 852 & 875 & 2,625 & 975 & 908 & 642 \\
\hline $\mathrm{Cr}$ (total) & 5,899 & 5,909 & 5,370 & 5,142 & 4,590 & 5,002 & 4,230 & 4,955 \\
\hline $\mathrm{Cu}$ & 13,567 & 12,179 & 12,878 & 12,255 & 12,008 & 13,615 & 11,674 & 10,335 \\
\hline $\mathrm{Hg}$ & 1,232 & 1,001 & 1,866 & 1,649 & 1,641 & 855 & 782 & 587 \\
\hline Mn & 4,676 & 2,271 & 5,584 & 3,348 & 2,381 & 2,020 & 1,644 & 1,200 \\
\hline $\mathrm{Ni}$ & 69,558 & 78,020 & 71,213 & 76,263 & 70,083 & 61,752 & 56,048 & 52,634 \\
\hline $\mathrm{Pb}$ & 54,331 & 30,819 & 41,610 & 37,188 & 47,919 & 45,500 & 44,347 & 28,562 \\
\hline $\mathrm{Sb}$ & 3,939 & 2,558 & 4,532 & 3,192 & 2,357 & 1,096 & 840 & 965 \\
\hline $\mathrm{Se}$ & 2,068 & 2,391 & 2,328 & 1,521 & 2,470 & 1,382 & 827 & 929 \\
\hline $\mathrm{Tl}$ & 622 & 446 & 517 & 427 & 789 & 705 & 588 & 425 \\
\hline $\mathrm{V}$ & 95,736 & 115,261 & 106,085 & 110,873 & 97,834 & 75,664 & 77,204 & 66,675 \\
\hline $\mathrm{Zn}$ & 53,790 & 47,855 & 46,144 & 42,001 & 60,256 & 34,774 & 28,890 & 23,081 \\
\hline Total incl. $\mathrm{CO}_{2}+$ other $\mathrm{GHGs}$ & $23,353,116,434$ & $22,551,797,119$ & $22,466,983,029$ & $22,261,822,755$ & $22,814,628,398$ & $22,431,455,919$ & $20,974,601,813$ & $19,220,370,821$ \\
\hline
\end{tabular}




\subsection{CML-method}

The CML-method, developed by the Institute of Environmental Sciences at the University of Leiden, has a problem-oriented midpoint approach, meaning that impacts are modeled at a midpoint somewhere in the cause (emissions) effect (damages) chain. Characterization factors for the calculation of impacts to human health are derived by means of the multimedia model USES-LCA, based on USES 2.0 but with some specific model settings to make it more suitable for impact assessment $[5,8]$. For the derivation of the CFs, a standard emission of $1 \times 10^{6} \mathrm{~kg}$ substance/day is released into one of the emission compartments air, freshwater, seawater, agricultural soil or industrial soil. So, for each pollutant, 5 different CFs are derived, according to the 5 "initial" emission compartments. The distribution module of the model then calculates an environmental steady-state concentration in the six environmental compartments air, freshwater, seawater, natural soil, agricultural soil and industrial soil (fate analysis). Based on these steady-state concentrations and characteristics such as respiration rate, daily intake of milk, fish, etc, the exposure module generates a predicted oral and inhalatory daily intake. The daily intakes are divided by a "human limit value" and aggregated to give a "risk characterization ratio". Finally this risk characterization ratio is divided by the risk characterization ratio of the reference substance 1,4-dichlorobenzene to give a $\mathrm{CF}$, expressed in $\mathrm{kg}$ 1,4- dichlorobenzene/kg. Huijbregts et al. [6] reported that uncertainty on input parameters and human variability is reflected in a lognormal distribution of the CFs with an uncertainty factor (defined as the ratio of the $97.5^{\text {th }}$ and $2.5^{\text {th }}$ percentile value) of $1.7 \times 10^{3}, 3.5 \times 10^{3}$ and $1.7 \times 10^{1}$ for emission to air of atrazine, $2,3,7,8-\mathrm{TCDD}$ and lead, respectively. For emissions to air, the differences in CFs resulting from choices 
in time horizon $(20,100,500$, infinite years) and special scale (continental, global) are not higher than 1.2 orders of magnitude [7].

\subsection{Eco-indicator 99-method}

The Eco-indicator 99 method, developed by PRé-consultants, has a damage-oriented (or endpoint) approach meaning that impacts on human health are expressed as an aggregation of damages (or endpoints) to the so-called damage category "human health". The model used to derive CFs for carcinogenic and respiratory effects consists of four steps. The first two steps are similar to the fate and exposure analysis of the CML-method. The fate is however modeled with EUSES, which is based on USES 1.0 multimedia model but with settings specific for Europe. In the third step, called effect analysis, the dose to which humans are exposed (due to the emission of $10^{4} \mathrm{~kg}$ of a substance per day to air, water, urban or industrial soil) is linked to the number of people affected by the considered effect. In the final step, called damage analysis, these health effects are linked to a number of disability adjusted life years (DALYs). DALYs correspond to the product of the number of people affected, the duration of the effect in years and a severity score ranging from 0 to 1 . In case of premature death, the number of years lost vs. the average life expectancy is considered. The CFs for damages caused by climate change and ozone layer depletion are estimated by means of specific fate, effect and damage analysis. Expressing all health effects in DALYs allows the aggregation of different endpoints. In order to quantify the effect of different possible models settings, Eco-indicator 99 makes a distinction between individualistic, hierarchic and egalitarian perspectives. Each of these perspectives stand for a different set of model settings and resulting CFs. Goedkoop and Spriensma [9] report that the uncertainty on the derived CFs 
mainly comes from uncertainties in the fate analysis. For most substances, the CFs appear lognormal distributed and for emissions to air the square of the geometric standard deviation $\left(\sigma_{\mathrm{g}}{ }^{2}\right)$ ranges from 2 to 80 , corresponding to an uncertainty factor (defined as the ratio of the $97.5^{\text {th }}$ and $2.5^{\text {th }}$ percentile value) of $4-1.6 \times 10^{3}$. In 2009 the models used in the CML and the Eco-Indicator 99 method were harmonized in terms of model settings and value choices. This resulted in the ReCiPe- method, which provides characterization factors on the midpoint (based on the CML approach) and endpoint level (based on the Eco-Indicator 99 approach). These characterization factors were not included in the comparison, merely because the USEtox-model is now promoted by UNEP and SETAC as overall consensus model (see Section 2.5).

\subsection{Environmental priority strategies - EPS-method}

The EPS method was originally developed for the comparison and quantification of environmental impacts of materials and processes at the product design phase [10]. In this method, the so-called "safeguard subject" human health is divided in 5 subcategories: life expectancy, severe morbidity, morbidity, severe nuisance, nuisance. For each substance, CFs for the relevant subcategories are derived, expressed in years of life lost (YOLL)/kg for the subcategory life expectancy and person.year/kg for the other subcategories. For most substances, first a "total category indicator" (in YOLL or person.years) is calculated, indicating the impact due to the average background concentration in the reference year (mostly 1990). Then this category indicator is divided by the amount of pollutant $(\mathrm{kg})$ emitted in the reference year (which is supposed to have led to the background concentration) leading to a characterization factor in YOLL/kg or person.year $/ \mathrm{kg}$. The CFs per 
subcategory are weighed and then aggregated to give an "overall characterization factor ${ }^{4} "$. The weighing factors correspond to the willingness to pay (WTP), expressed in euro, to avoid one YOLL or one person.year, respectively. The "overall characterization factor" is expressed in euro/kg; subsequently, the calculated impacts are given in euro or so called "environmental load units (ELU)". CFs exist for emissions to air, water and soil. Due to uncertainties, the subcategory CFs are typically log normal distributed, and for emissions to air the geometric standard deviation $\left(\sigma_{\mathrm{g}}\right)$ ranges from 2.2 to 10 , corresponding to an uncertainty factor (defined as the ratio of the $97.5^{\text {th }}$ and $2.5^{\text {th }}$ percentile value) of $2.3 \times 10^{1}-1.0 \times 10^{4}$.

\subsection{EDIP-method}

The EDIP method was developed under the Danish Environmental Design of Industrial Products program [11] and has a midpoint oriented approach. As for the CML- and Eco-indictor'99 methods, a fate-exposure-effect model is used to derive characterization factors. The model is however simpler and more transparent as it is based on a limited set of key properties. Characterization factors are derived for the environmental compartments air, water and soil. They equal the product of a fate, intake, transfer and biodegradability factor divided by a human toxicity factor. The fate factor expresses which fraction of the emitted amount of a substance contributes to the impact on human health and varies between 0 and 1 depending on the tropospheric half-life value and Henry's law constant of the substance. The intake factor expresses the average human ingestion of the considered environmental

\footnotetext{
${ }^{4}$ EPS is the only method in which weighing occurs before aggregation of impacts. For reasons of consistency, the weighed and aggregated characterisation factors for the sub impact categories are called "overall characterisation factors".
} 
compartment, either directly (e.g. $\mathrm{kg}$ air/kg body weight.day) or indirectly (e.g. $\mathrm{kg}$ milk/kg body weight.day, $\mathrm{kg}$ plants/kg body weight.day). In the case of indirect exposure, the transfer factor expresses the transfer efficiency for the substance from the compartment (e.g. water, soil) to the medium ingested (eg. plants, meat, fish) $\left(\mathrm{m}^{3}\right.$ compartment $/ \mathrm{kg}$ medium e.g. $\mathrm{m}^{3} / \mathrm{kg}$ plant). Key parameters influencing the transfer factor are e.g. the octanol-water partition coefficient, the relative water content of the soil, etc. The biodegradability factor varies between 0.2 and 1 and is based on the outcome of standardized lab tests (OECD-tests). The human toxicity factor is either a human reference dose or a human reference concentration. Wenzel and Hauschild [11] did not quantify the uncertainties on the EDIP-CFs.

\subsection{USEtox - the UNEP-SETAC toxicity model}

Under initiative of UNEP and SETAC, model developers built a scientific consensus model for the derivation of characterization factors for human health impact assessment. This model, called USEtox, is the outcome of a detailed comparison of existing models (including USES-LCA and EDIP) by the model developers [12,14]. As in the USES and EDIP model, USEtox calculates characterization factors by means of a fate, an exposure and an effect module. The fate and exposure modules are very similar to the modules in the USES-LCA model (see section 2.1). In the effect module of USEtox, the exposure due to the emission of a certain amount of a substance is linked to the number of people affected (disease cases) by multiplying the dose by an effect-factor based on $\mathrm{ED}_{50} \mathrm{~s}^{5}$. Four effect groups are considered: cancer from ingestion exposure, non-cancer effects from ingestion exposure, cancer

\footnotetext{
${ }^{5} \mathrm{ED}_{50}$ is the lifetime daily dose resulting in a probability of effect of 0.5
} 
from inhalation exposure and non-cancer effects from inhalation exposure. The number of people affected by each of these effects are aggregated resulting in a characterization factor which is determined for the emission compartments urban air, rural air, freshwater or agricultural soil and is expressed in cases $/ \mathrm{kg}$ or so-called comparative toxic units (CTU). The precision of the CFs provided by USEtox is within a factor 100-1000 [12]. A distinction is made between interim and recommended CFs reflecting the level of reliability of the calculations in a qualitative way.

\subsection{Impact estimation based on minimal risk levels -MRC/MRD-method}

In view of the large uncertainties on the CFs derived by means of fate-exposure-effect models it seemed interesting to compare with a more simple approach in which the CFs are replaced by the reciprocal of the MRD or MRC. These parameters were found most suitable because in general industrial emissions are emitted continuously over time (no pulse emissions) and result in chronic human exposure to relatively low doses. The MRC is relevant for substances to which humans are primarily exposed by inhalation. Toxicological profiles from the Agency for Toxic Substances and Disease Registry and Human health criteria from the World Health Organisation [16-37] point out that this is the case for volatile organic compounds (e.g. benzene, toluene, 1,2dichloroethane) and inorganic gases such as $\mathrm{SO}_{\mathrm{X}}$ and $\mathrm{NO}_{\mathrm{X}}$. The MRD is relevant for substances to which humans are primarily exposed to by ingestion of food, as is the case for heavy metals (e.g. cadmium, chromium, mercury, lead) and persistent organic pollutants (POPs, e.g. PCBs and PCDD/Fs). As a consequence, impacts of organic substances and heavy metals have to be assessed separately; it is not possible to calculate the impact of the emission inventory as a whole. This approach does not 
take into account differences in environmental fate and exposure between substances. It is intrinsically assumed that fate and exposure are equal for all substances, which is not the case, so this assumption introduces uncertainty on the results. It can however be questioned whether this uncertainty is more important than the uncertainty in the model-settings and -parameters. The MRCs and MRDs only take in to account the most sensitive non-cancer effect, which can be quite different from substance to substance. So, when the total impact on human health is calculated, the impacts of the individual substances based on MRCs or MRDs for different health effects, are aggregated. The fact that there is not necessarily a scientific basis to do so was also recognized by Hauschild and Wenzel [11]. MRCs and MRDs contain some degree of uncertainty, resulting from extrapolation of no-observed-adverse-effect levels from animals to humans and from differences in sensitivity between humans [16-37].

\subsection{Emission data}

The emission data used to compare the assessment methods were taken from the core emission data set of the Flemish industry for the years 2000 to 2007 reported by the Flemish Environmental Agency [15]. These data are readily available and reliable because they have been collected following the same method each year and because they are verified by the Flemish government [1]. From the data set, the substances for which a CF exists in at least one of the compared impact assessment methods were selected. Table 1 gives the industrial emissions of the selected substances for the years 2000 to 2007 .

\subsection{Comparison procedure}

Table 2 gives the available CFs and 1/MRC- and 1/MRD-values for the considered substances. By means of these factors, the total impact on human health of the 
Flemish industrial emissions to air for the years 2000 to 2007 is calculated for each method. This total impact corresponds to the sum of the impacts of all substances for which the method provides a CF. In section 3, the trend of the total impact on human health is compared for the CML-, Eco-indicator 99-, EPS and EDIP- method. The USEtox-method is not included in this comparison, because it does not yet provide CFs for the heavy metals in the emission inventory. The MRC/MRD-method is also not included, because, as explained in section 2.6, it can only be used to calculate the impact of heavy metals and organic substances separately. For the comparison of the trends, in each method the yearly impacts are normalized relative to the year 2000 . Also the relative contribution of the different substances to the total impact for the year 2006 is compared between methods. Since the different assessment methods express the potential impact on human health in quite different units, it is impossible to directly compare the results. Therefore the relative contribution of each substance to the total impact, which is set equal to 1.00 , is calculated for each method. Not all the assessment methods provide CFs for all of the substances in the inventory, which makes it somewhat difficult to evaluate the difference in relative contribution of a substance between the different methods. A third comparison is made by calculating the total impact of a set of organic substances and a set of heavy metals for which a $\mathrm{CF}$ is available in a maximum number of the considered assessment methods. Because the latter two comparisons only consider substances for which CFs or 1/MRC- and 1/MRD-values are provided by each assessment method, the evaluation of the differences in relative contributions is more straightforward.

\section{Results and discussion}

\subsection{Trend and comparison of total impact}


Figure 1 gives the trends of the yearly total impact on human health of the Flemish industrial emissions calculated with the CML-, eco-indicator 99-, EPS and EDIPmethod and normalized relative to the total impact in the year 2000.

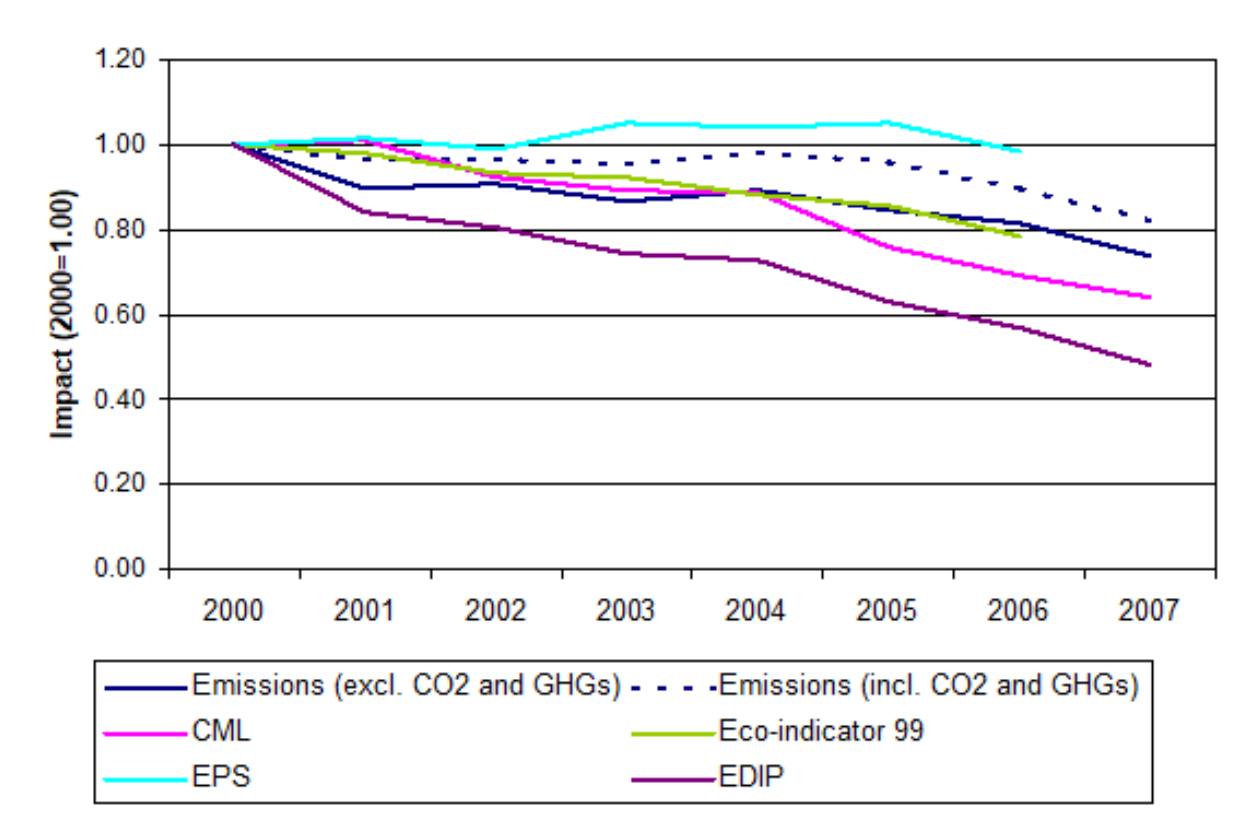

Figure 1: Total impact on human health of the Flemish industrial emissions to air, calculated with the CML-, Eco-indicator 99-, EPS and EDIP- method (years 2000 to 2007).

For the Eco-indicator 99- and EPS-method the total impact was not calculated for 2007, since the emissions of ozone depleting substances were not yet inventoried at the beginning of this study. As a reference, the trend of the total Flemish industrial emissions, including and excluding the $\mathrm{CO}_{2}$-emissions is given. This distinction is made because the $\mathrm{CO}_{2}$ - and greenhouse gas emissions account for ca. $97 \%$ of the total emissions and dominate the trend of the other emissions. Furthermore only the Ecoindicator 99- and EPS-method take the impacts on human health caused by climate change in to account. From figure 1 it can be concluded that all the total impacts 
calculated by the assessment methods follow the decreasing trend of the emissions, except for the EPS-method, which shows little impact change over the years. If impacts to human health are calculated with the EDIP-CFs, a decrease of ca. $40 \%$ between 2006 and 2000 is noticed; the impact calculated with CML- and Ecoindicator $99-\mathrm{CFs}$ decreased with ca. $30 \%$ and ca. $20 \%$ over the same period, respectively.

Figure 2 gives the relative contribution of the different substances from the emission inventory to the total impact on human health in 2006 for the CML-, Eco-indicator 99-, EPS- and EDIP-method.

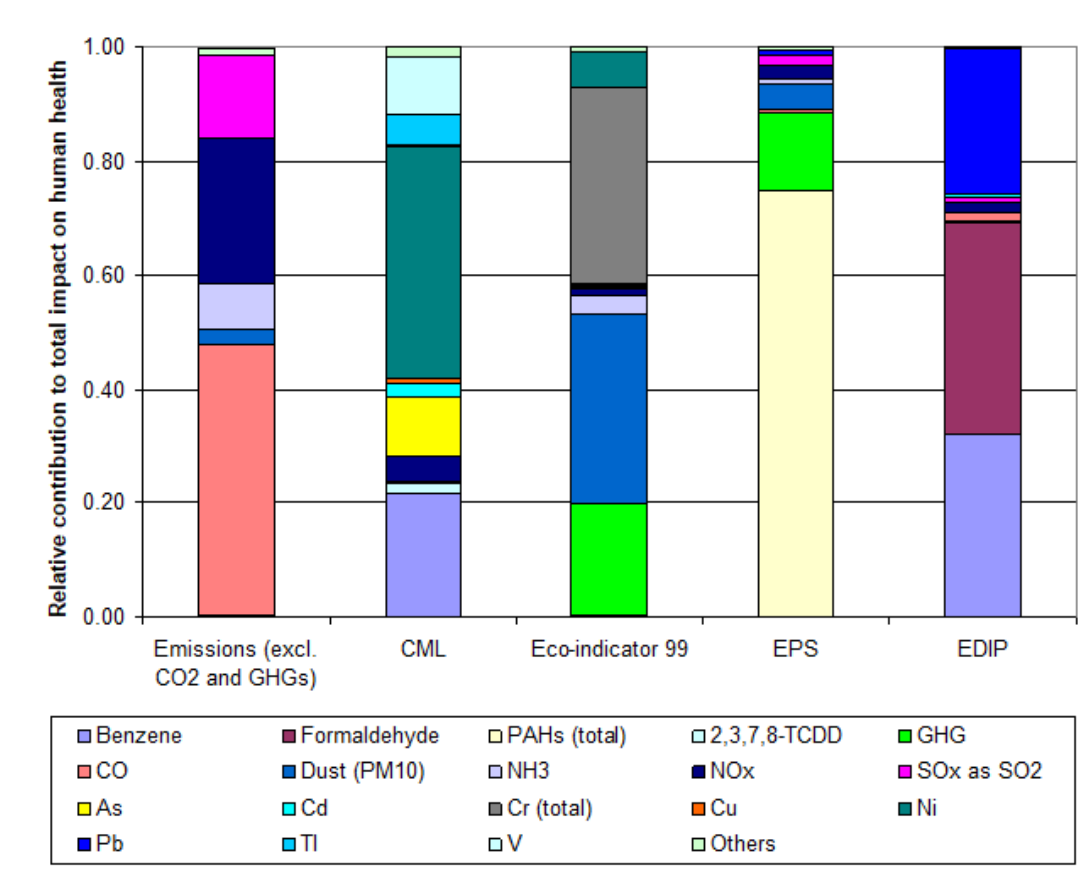

Figure 2: Relative contribution of the substances emitted to air by the Flemish industry to the total impact on human health calculated with the CML-, Eco-indicator 99-, EPS and EDIP- method (year 2006).

The relative contribution of the considered substances is clearly different for each assessment method. The differences in the models used to derive the CFs and the 
different value choices and points of view in each method lead to considerable differences in total impact calculation. In the CML-method, ca $70 \%$ of the total impact is accounted for by heavy metals with arsenic, nickel and vanadium being most important; ca. $20 \%$ of the impact is attributed to benzene and ca. $5 \%$ to $\mathrm{NO}_{\mathrm{X}}$. Eco-indicator 99 and EPS are the only assessment methods that take health effects of global warming in to account and provide CFs for greenhouse gases (GHGs). In case of Eco-indicator 99, the GHGs account for ca. $20 \%$ of the total impact on human health. Other substances with important contributions to the total impact in this method are PM10 (ca. 35\%), chromium (ca. 35\%, assessed as Cr VI) and nickel (ca. $6 \%$ ). In the EPS method ca. $75 \%$ of the total impact is accounted for by the polyaromatic hydrocarbons (PAHs), followed by the GHGs (ca. 14\%) and PM10 (ca. 4\%). According to the EDIP-method the main contributors to the total impact on human health are formaldehyde (ca. 40\%), benzene (ca. 30\%) and lead (ca. 25\%). The main contributors to the total impact calculated with each method are largely different. This indicates that the correspondence between the trends in Figure 1 is the result of a more or less equal decrease between 2000 and 2007 of the emissions of the main contributors. Indeed, the emission of nickel and benzene decreased by ca. 20 and 55\%, respectively (CML-method); the emission of PM10, chromium and GHGs decreased by ca. 20, 30, and 10\% respectively (Eco-indicator 99-method) and the emission of formaldehyde and benzene decreased by ca. 45 and 55\%, respectively. The emission of PAH fluctuated around 190,000 kg/year, explaining the trend of the total impact calculated with the EPS-CFs (dark grey line in Figure 1). As already stated in Section 2.8, not all the assessment methods provide CFs for all of the substances in the inventory. Eco-indicator 99 and EPS do e.g. not provide a CF for 
the heavy metal vanadium, which has a significant contribution to the total impact calculated with the CML CFs. The ability of PAHs to enter the food chain and cause damage to human health was demonstrated by Rey-Salgueiro et al. [38]. The EDIPmethod however does not provide a CF for PAHs, which account in the emission inventory of the Flemish industry for the year 2006 for ca. $75 \%$ of the total impact if EPS CFs are used. These examples stress the importance of the availability of CFs for all chemicals.

The differences between methods should however be interpreted taking in to account the uncertainty on the CFs. As explained by Rosenaum et al. [12], an uncertainty of e.g. a factor 1,000 means that relative contributions of $0.01,0.05$ or 0.90 to the total impact are essentially equal. According to the same authors, disregarding this fact has been a major cause of the variability of these factors across impact assessment methods. They advise to use the CFs only to identify the most important substances in the emission inventory i.e. the substances with a relative contribution to the total impact of more than 0.001 . Table 3 gives the relative contributions of the substances represented in figure 2 for the CML-, Eco-indicator 99-, EPS- and EDIP method. When the relative contributions for this particular emission inventory are interpreted as advised by Rosenbaum et al. [12] (considering the substances for which CFs exist in at least 3 methods), the considered methods correspond on the significant contribution of the inorganic gases $\mathrm{NH}_{3}, \mathrm{NO}_{\mathrm{X}}$ and $\mathrm{SO}_{\mathrm{X}}$ and PM10. They also indicate that the relative contribution of the organic emissions (toluene, 1,2-dichloroethane, tetrachloroethene and vinylchloride) is insignificant. The Eco-indicator 99- and EPSmethod lead to the same conclusion on the relative contribution of the GHGs and the ozone depleting substances. Despite these correspondences, some major differences 
remain between the four considered assessment methods. For this particular emission inventory, benzene has a significant contribution in the CML- and EDIP-method but in the eco-indicator 99 and EPS-method it is insignificant (contribution $<0.001$ ). Formaldehyde and xylenes are only of significant importance if the EDIP-CFs are used. The PCDD/F-emissions (expressed as 2,4,7,8-TCDD-equivalents) appear only important if CML-CFs are applied. According to the CML-, Eco-indicator 99- and EDIP-method, arsenic and cadmium have significant contributions to the total impact. This is however not the case for the EPS-method. Also for chromium and nickel the different sets of CFs lead to different conclusions regarding the relative importance. The conclusions about the differences between methods are only valid for the considered emissions and are also influenced by the fact that not all the substances in the inventory have CFs in all the methods, as already mentioned. Therefore, in Section 3.2 a comparison is made for substances that have a CF in all the assessment methods. 
Table 3: Characterisation factors for human toxicity applied in the different assessment methods and 1/MRC- and 1/MRD-values

\begin{tabular}{|c|c|c|c|c|c|c|c|c|}
\hline & $\begin{array}{c}\text { CML-method } \\
\text { kg 1,4-DCB eq./kg }\end{array}$ & $\begin{array}{c}\text { Eco-indicator'99 } \\
\text { DALY/kg }\end{array}$ & $\begin{array}{l}\text { EPS-method } \\
\text { ELU/kg }\end{array}$ & $\begin{array}{l}\text { EDIP-method } \\
\mathrm{m}^{3} / \mathrm{g}^{\mathrm{d}}\end{array}$ & $\begin{array}{l}\text { USEtox } \\
\text { CTU/kg }\end{array}$ & $\begin{array}{l}\text { 1/MRC } \\
\left(\mathrm{mg} / \mathrm{m}^{3}\right)^{-1}\end{array}$ & $\begin{array}{c}\text { 1/MRD } \\
\left(\mathrm{mg} / \mathrm{kg}_{\mathrm{bw}} \cdot \text { day }\right)^{-1}\end{array}$ & $\begin{array}{l}\text { Reference } \\
\text { MRC/MRD }\end{array}$ \\
\hline \multicolumn{9}{|l|}{$\begin{array}{l}\text { Organic substances } \\
\text { (Volatile Organic } \\
\text { Compounds) }\end{array}$} \\
\hline Benzene & $1.90 \mathrm{E}+03$ & $3.05 \mathrm{E}-06$ & $3.41 \mathrm{E}+00$ & $1.00 \mathrm{E}+07$ & $9.65 \mathrm{E}-09$ & $1.04 \mathrm{E}+02$ & & $\begin{array}{c}\text { MRL chronic duration } \\
\text { inhalation taken from } \\
{[16]}\end{array}$ \\
\hline Formaldehyde & 8.31E-01 & $2.10 \mathrm{E}-06$ & $5.93 \mathrm{E}+00$ & $1.30 \mathrm{E}+07$ & $1.17 \mathrm{E}-07$ & $1.02 \mathrm{E}+02$ & & $\begin{array}{c}\text { MRL chronic duration } \\
\text { inhalation taken from } \\
{[17]}\end{array}$ \\
\hline PAHs (total) & & $1.70 \mathrm{E}-04$ & $6.43 \mathrm{E}+04$ & & & & & \\
\hline Toluene & 3.27E-01 & $1.36 \mathrm{E}-06$ & $1.61 \mathrm{E}+00$ & $2.50 \mathrm{E}+03$ & $2.18 \mathrm{E}-09$ & $3.33 \mathrm{E}+00$ & & $\begin{array}{c}\text { MRL chronic duration } \\
\text { inhalation taken from } \\
{[18]}\end{array}$ \\
\hline Xylene-isomers & $1.90 \mathrm{E}+03$ & $2.21 \mathrm{E}-06$ & & $6.70 \mathrm{E}+03$ & $1.95 \mathrm{E}-09$ & $4.61 \mathrm{E}+00$ & & $\begin{array}{c}\text { MRL chronic duration } \\
\text { inhalation taken from } \\
{[19]}\end{array}$ \\
\hline \multicolumn{9}{|l|}{$\begin{array}{l}\text { Chlorinated organic } \\
\text { substances }\end{array}$} \\
\hline 1,2-dichloroethane & $6.81 \mathrm{E}+00$ & $2.98 \mathrm{E}-05$ & & $5.00 \mathrm{E}+04$ & $1.68 \mathrm{E}-07$ & 4.12E-01 & & $\begin{array}{c}\text { MRL chronic duration } \\
\text { inhalation taken from } \\
{[20]}\end{array}$ \\
\hline 2,3,7,8-TCDD & $1.93 \mathrm{E}+09$ & $1.79 \mathrm{E}+02$ & & $2.90 \mathrm{E}+10$ & $8.80 \mathrm{E}-01$ & & $1.00 \mathrm{E}+09$ & TDI taken from [21] \\
\hline Tetrachloroethene & $5.50 \mathrm{E}+00$ & $5.44 \mathrm{E}-07$ & & $2.90 \mathrm{E}+04$ & $3.05 \mathrm{E}-07$ & $3.68 \mathrm{E}+00$ & & $\begin{array}{c}\text { MRL chronic duration } \\
\text { inhalation taken from } \\
\text { [22] }\end{array}$ \\
\hline Vinylchloride & $8.43 \mathrm{E}+01$ & $2.09 \mathrm{E}-07$ & & $3.90 \mathrm{E}+05$ & $3.02 \mathrm{E}-07$ & $1.00 \mathrm{E}+01$ & & $\begin{array}{c}\text { EPA RfC taken from } \\
{[23]}\end{array}$ \\
\hline \multicolumn{9}{|c|}{ Inorganic substances } \\
\hline Carbon disulphide & $2.41 \mathrm{E}+00$ & & & & & & & \\
\hline $\mathrm{CO}$ & & & $3.28 \mathrm{E}-01$ & $8.30 \mathrm{E}+02$ & & & & \\
\hline Dust (PM10) & $8.20 \mathrm{E}-01$ & $3.75 \mathrm{E}-04$ & $3.60 \mathrm{E}+01$ & & & & & \\
\hline $\mathrm{H}_{2} \mathrm{~S}$ & $2.20 \mathrm{E}-01$ & & $6.82 \mathrm{E}+00$ & & & & & \\
\hline $\mathrm{NH}_{3}$ & $1.00 \mathrm{E}-01$ & $1.50 \mathrm{E}-05$ & $3.23 \mathrm{E}+00$ & & & & & \\
\hline $\mathrm{NO}_{\mathrm{x}}$ & $1.20 \mathrm{E}+00$ & $1.28 \mathrm{E}-06$ & $2.15 \mathrm{E}+00$ & $2.00 \mathrm{E}+03$ & & $2.50 \mathrm{E}+01$ & & $\begin{array}{l}\text { WHO long term } \\
\text { guidance value taken } \\
\text { from [24] }\end{array}$ \\
\hline
\end{tabular}




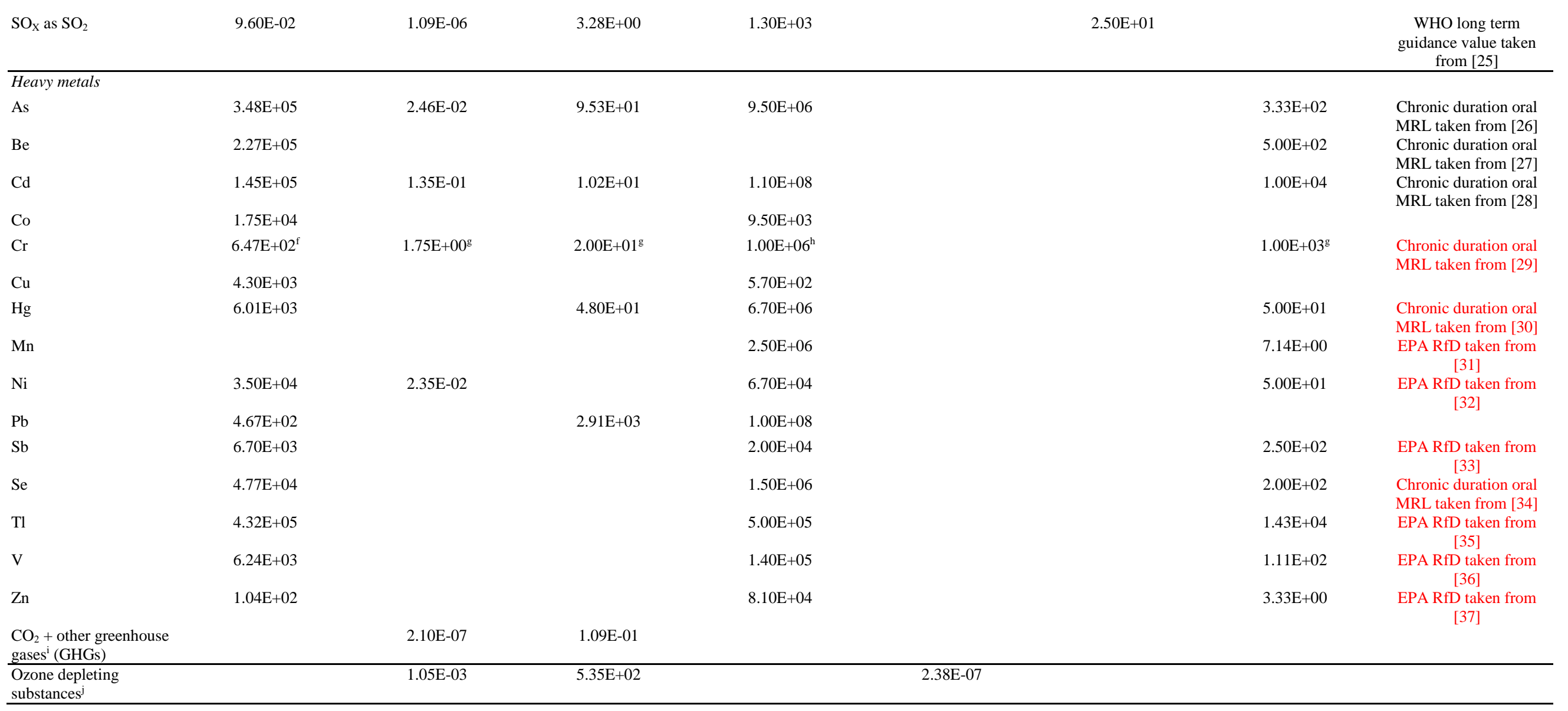


${ }^{a}$ taken from CML database at http://cml.leiden.edu/software/data-cmlia.html

${ }^{\mathrm{b}}$ taken from [9] Methodology Annex (hierachic perspective)

${ }^{c}$ taken from [10]

d taken from [11]

e taken from [12]

gexposure to $\mathrm{Cr}(\mathrm{III})$
${ }^{\mathrm{g}}$ exposure to $\mathrm{Cr}(\mathrm{VI})$

specified

${ }^{i}$ expressed in $\mathrm{CO}_{2}$-eqiuvalents (GWP IPCC 1996)

$\mathrm{j}$ expressed in CFC-11-eqiuvalents (ODP UNEP 2000) 


\subsection{Comparison with the USEtox- and MRC/MRD-method}

When emissions of organic substances and of heavy metal are assessed separately, also the CFs derived by the USEtox-model and the MRC/MRD-method can be included in the comparison. Figure 3 shows the trends (years 2000 to 2007) of the total impact on human health of the seven organic substances in the emission inventory for which CFs are provided by all the methods.

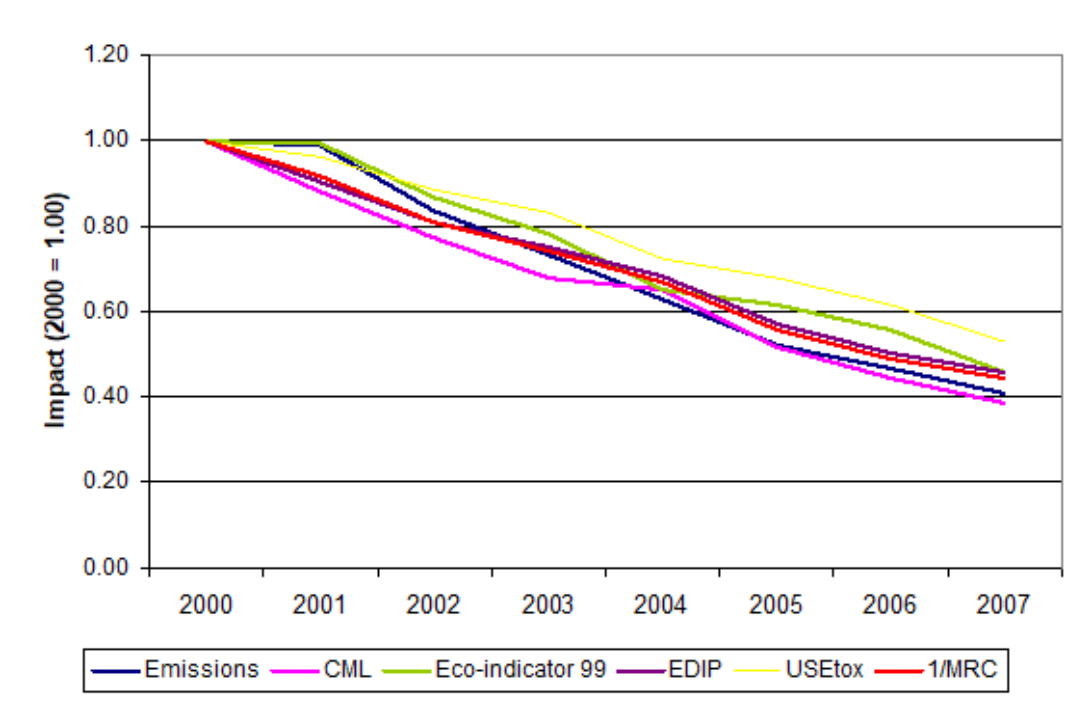

Figure 3: Total impact on human health of selected organic substances emitted to air by the Flemish industry, calculated with the CML-, Eco-indicator 99-, EDIP-, USEtox - and MRC/MRD-method (years 2000 to 2007).

Since the EPS-method only provides CFs for four of the seven organic substances (Table 2), it is not included in this comparison. All methods follow the decreasing trend of the emissions and the differences are less pronounced than if all emissions are included (Figure 1). Figure 4 shows the relative contribution of the selected organic substances in each method. The differences in relative contributions between 
the methods are less pronounced than when all substances in the emission inventory are considered (figure 2).

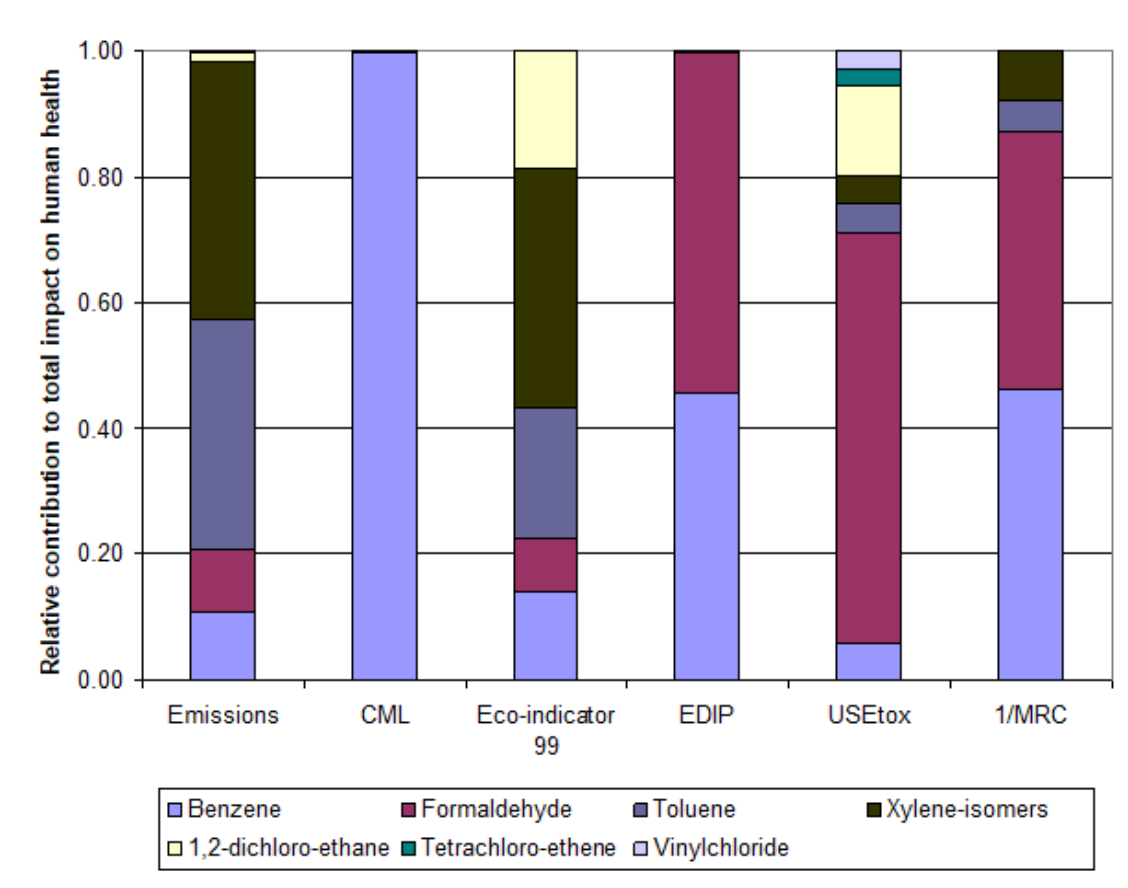

Figure 4: Relative contribution of selected organic substances emitted to air by the Flemish industry to the total impact on human health, calculated with the CML-, Ecoindicator 99-, EDIP-, USEtox - and MRC/MRD-method (year 2006)

There is a good correspondence between the Eco-indicator 99-, USEtox- and MRC/MRD-method, according to which benzene, formaldehyde, toluene and the xylenes are the most important contributors. Only Eco-indicator 99 and USEtox also indicate 1,2-dichloroethane as a significant contributor. When the CML-CFs are used to assess the impact on human health, only benzene is of any importance. According to the EDIP-method, benzene and formaldehyde contribute each for ca. $50 \%$ to the total impact (Table 5). When the results in Figure 4 are interpreted as indicated by Rosenbaum et al. [12], only benzene and xylene-isomers have significant 
contributions (> 0.001) in all five methods (see Table 4). The Eco-indicator 99 and the MRC/MRD-method however, indicate the same pollutants as significant contributors to the total impact on human health, except for 1,2-dichloro-ethane, which is only significant according to Eco-indicator 99. In the USEtox-method also tetrachloroethylene and vinylchloride and thus all the substances considered in this comparison have significant contributions.

Table 4: Comparison of the relative contributions to the total impact on human health in different assessment methods

\begin{tabular}{|c|c|c|c|c|}
\hline & CML & Eco-indicator '99 & EPS & EDIP \\
\hline \multicolumn{5}{|l|}{$\begin{array}{l}\text { Organic substances (Volatile } \\
\text { Organic Compounds) }\end{array}$} \\
\hline Benzene & 0.217 & $<0.001$ & $<0.001$ & 0.319 \\
\hline Formaldehyde & $<0.001$ & $<0.001$ & $<0.001$ & 0.375 \\
\hline PAHs (total) & & 0.001 & 0.748 & \\
\hline Toluene & $<0.001$ & $<0.001$ & $<0.001$ & $<0.001$ \\
\hline Xylene-isomers & $<0.001$ & $<0.001$ & & 0.001 \\
\hline \multicolumn{5}{|l|}{ Chlorinated organic substances } \\
\hline 1,2-dichloroethane & $<0.001$ & $<0.001$ & & $<0.001$ \\
\hline $2,3,7,8-\mathrm{TCDD}$ & 0.017 & $<0.001$ & & $<0.001$ \\
\hline Tetrachloro-ethene & $<0.001$ & $<0.001$ & & $<0.001$ \\
\hline Vinylchloride & $<0.001$ & $<0.001$ & & $<0.001$ \\
\hline $\mathrm{CO}_{2}+$ other greenhouse gases & & 0.197 & 0.137 & \\
\hline Ozone depleting substances & & 0.009 & 0.006 & \\
\hline \multicolumn{5}{|l|}{ Inorganic substances } \\
\hline Carbon disulphide & $<0.001$ & & & \\
\hline $\mathrm{CO}$ & & & 0.007 & 0.015 \\
\hline Dust (PM10) & 0.003 & 0.334 & 0.043 & \\
\hline $\mathrm{NH}_{3}$ & 0.001 & 0.032 & 0.009 & \\
\hline NOx & 0.042 & 0.010 & 0.023 & 0.020 \\
\hline$\underline{\mathrm{SOx} \text { as } \mathrm{SO}_{2}}$ & 0.002 & 0.005 & 0.019 & 0.007 \\
\hline \multicolumn{5}{|l|}{ Heavy metals } \\
\hline As & 0.106 & 0.002 & $<0.001$ & 0.001 \\
\hline $\mathrm{Be}$ & 0.004 & & & \\
\hline $\mathrm{Cd}$ & 0.022 & 0.005 & $<0.001$ & 0.005 \\
\hline Co & 0.003 & & & $<0.001$ \\
\hline $\mathrm{Cr}$ (total) & 0.001 & 0.343 & $<0.001$ & $<0.001$ \\
\hline $\mathrm{Cu}$ & 0.010 & & & $<0.001$ \\
\hline $\mathrm{Hg}$ & 0.001 & & $<0.001$ & $<0.001$ \\
\hline $\mathrm{Mn}$ & & & & $<0.001$ \\
\hline $\mathrm{Ni}$ & 0.404 & 0.061 & & $<0.001$ \\
\hline $\mathrm{Pb}$ & 0.004 & & 0.008 & 0.255 \\
\hline $\mathrm{Sb}$ & 0.001 & & & $<0.001$ \\
\hline $\mathrm{Se}$ & 0.008 & & & $<0.001$ \\
\hline $\mathrm{Tl}$ & 0.052 & & & $<0.001$ \\
\hline V & 0.099 & & & 0.001 \\
\hline
\end{tabular}


Table 5: Comparison of the relative contributions to the total impact on human health of the selected organic substances in different assessment methods

\begin{tabular}{lccccc} 
& CML & Eco-indicator 99 & EDIP & USEtox & MRC/MRD \\
\hline Benzene & 0.925 & 0.085 & 0.458 & 0.042 & 0.345 \\
Formaldehyde & 0.000 & 0.053 & 0.539 & 0.459 & 0.305 \\
Toluene & $<0.001$ & 0.129 & $<0.001$ & 0.032 & 0.037 \\
Xylene-isomers & 0.001 & 0.232 & 0.001 & 0.032 & 0.057 \\
1,2-dichloroethane & $<0.001$ & 0.114 & $<0.001$ & 0.101 & $<0.001$ \\
$2,3,7,8-$ TCDD & 0.072 & 0.385 & $<0.001$ & 0.295 & 0.254 \\
Tetrachloro-ethene & $<0.001$ & $<0.001$ & $<0.001$ & 0.019 & $<0.001$ \\
Vinylchloride & $<0.001$ & $<0.001$ & $<0.001$ & 0.020 & $<0.001$
\end{tabular}

For six of the seven considered emissions, a simple estimation of the impact by dividing the emitted mass by the MRC, leads to the same conclusion on the relative contribution to the total impact than when CFs of the Eco-indicator 99- are used. Figure 5 shows the trends (years 2000 to 2007) of the impacts to human health of the ten metals in the emission inventory for which CFs are provided by the CML-, EDIPand MRC/MRD-method. Eco-indicator 99 and EPS are not included in the comparison because they only provide CFs for 4 of the 10 metals (see table 2). USEtox does not yet provide CFs for metals and is thus also not included. As for the complete inventory and the organic substances, the impacts calculated by the three methods follow the decreasing trend of the emissions. Figure 6 shows the relative contribution of the ten metals in each method. Although considerable differences remain between methods, they appear less pronounced than when all the substances 
in the emission inventory are considered together. Arsenic, cadmium, nickel, thallium and vanadium have major contributions in all the methods.

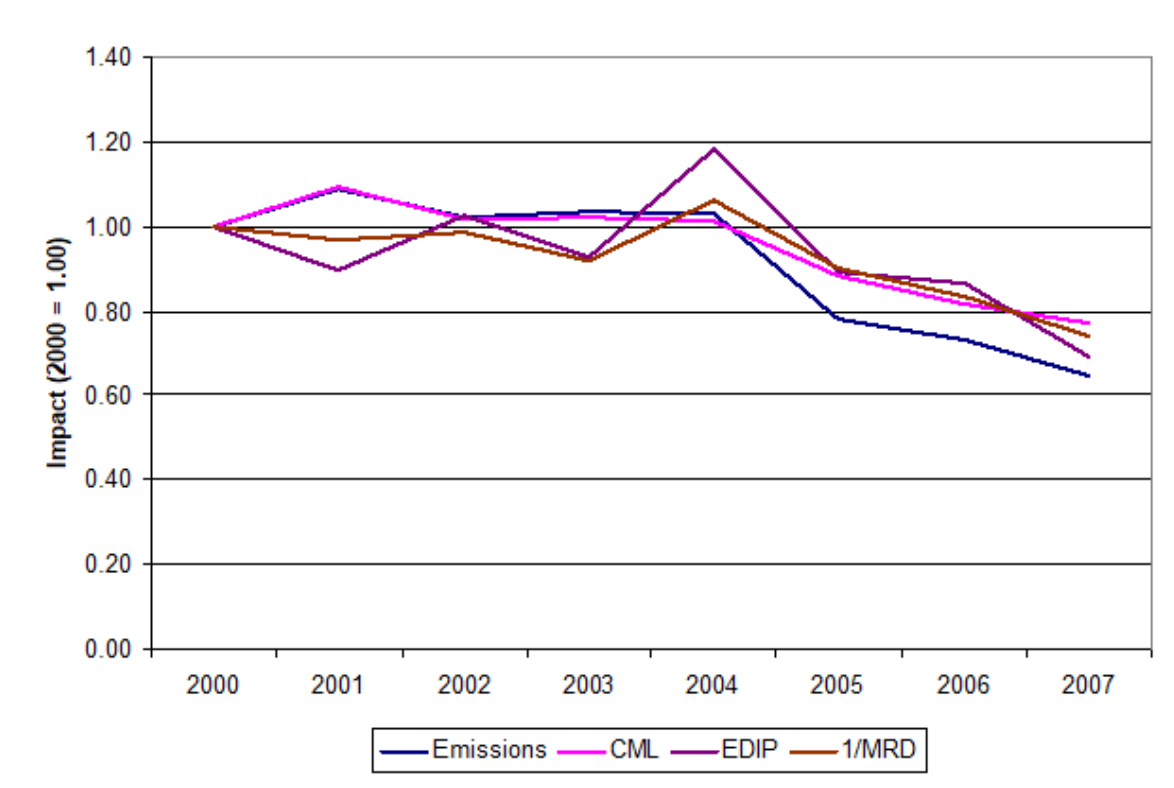

Figure 5: Total impact on human health of selected heavy metals emitted to air by the Flemish industry, calculated with the CML-, EDIP- and MRC/MRD-method (years 2000 to 2007)

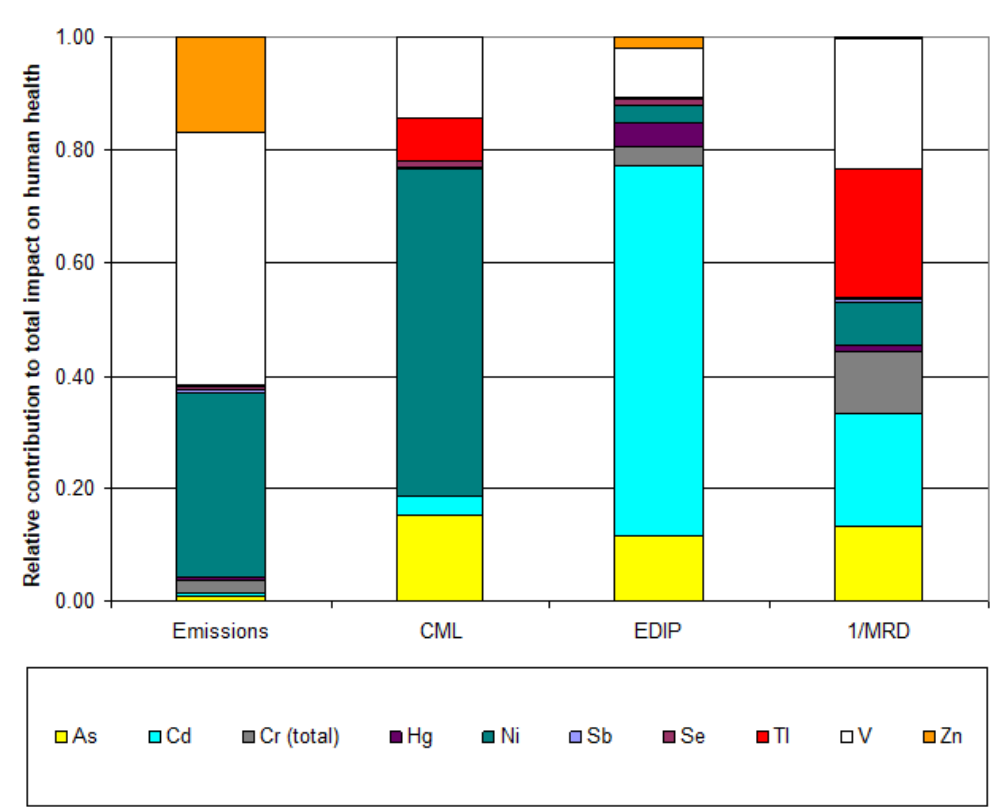


Figure 6: Relative contribution of selected heavy metals emitted to air by the Flemish industry to the total impact on human health, calculated with the CML-, EDIP- and MRC/MRD-method (year 2006).

When the results in figure 6 are interpreted as indicated by Rosenbaum et al. [12], all metals have significant contributions in all methods, except for chromium, the contribution of which is not significant according to the CML-CFs (CML-CF for Cr III, the MRD is for exposure to Cr VI, the EDIP-method does not specify the oxidation state) and antimony, the contribution of which is not significant according to the EDIP-CFs (Table 6). Dividing the emissions of heavy metals by MRDs instead of applying model based CFs, leads to more or less the same conclusions about both the trend of the impacts over time and the relative contributions of the individual substances.

Table 6: Comparison of the relative contributions to the total impact on human health of metals in different assessment methods

\begin{tabular}{lccc} 
& CML & EDIP & MRC/MRD \\
\hline As & 0.153 & 0.115 & 0.133 \\
$\mathrm{Cd}$ & 0.031 & 0.658 & 0.197 \\
$\mathrm{Cr}$ (total) & $<0.001$ & 0.034 & 0.114 \\
$\mathrm{Hg}$ & 0.001 & 0.043 & 0.011 \\
$\mathrm{Ni}$ & 0.581 & 0.031 & 0.075 \\
$\mathrm{Sb}$ & 0.002 & $<0.001$ & 0.006 \\
$\mathrm{Se}$ & 0.012 & 0.010 & 0.004 \\
$\mathrm{Tl}$ & 0.075 & 0.002 & 0.226 \\
$\mathrm{~V}$ & 0.143 & 0.088 & 0.231 \\
$\mathrm{Zn}$ & 0.001 & 0.019 & 0.003
\end{tabular}




\section{Conclusion}

The impact on human health of substances emitted to air can be calculated with CFs provided by different assessment methods. When CML-, Eco-indicator 99, EPSEDIP- and USEtox-CFs are applied to a complete industrial emission inventory, it appears from the results that the choice of the CFs can highly influence the conclusions on the trend of the impact over time and on the relative contribution of individual substances in the inventory. This indicates the need for arguing why certain CFs are chosen for the human health impact assessment of a particular emission inventory. In order to do so, practitioners should know and understand the different points of view and value choices of the available assessment methods. Furthermore, they should be aware of the large uncertainties on the calculated impact and should quantify this uncertainty before making conclusions on the relative contribution of individual substances.

If organic substances and heavy metals in the industrial emission inventory are assessed separately, the differences between methods are less pronounced. So, evaluating the impact on human health in categories could make the result less dependent on the applied method. In case of separate assessment of organic substances and heavy metals, the relative contributions of individual substances to the total impact on human health calculated by dividing the emitted mass by the MRC for organic substances or by the MRD for metals, are similar to the contributions calculated with model based CFs. If separate assessment of organics and heavy metals is an option, this approach could be a quick and easy to understand alternative to the model-based methods for human impact assessment. 
The validity of this approach should however be further investigated by using it to calculate the impact on human health of a larger variety of organic and inorganic emissions and comparing the results with other assessment methods. It should also be investigated if a similar simple methodology can be derived and validated for emission of substances to water.

\section{Acknowledgements}

Sarah Polspoel is gratefully acknowledged for doing preparatory work. The authors also thank Prof. Jan Vermant (University of Leuven, Department of Chemical Engineering) for constructive remarks.

\section{References}

[1] J. Van Caneghem, C. Block, H. Van Hooste, C. Vandecasteele, Eco-efficiency trends of the Flemish industry: decoupling of environmental impact from economic growth, Submitted to J. Clean. Prod.

[2] J. Van Caneghem, C. Block, P. Cramm, M. Mortier, C. Vandecasteele, Improving eco-efficiency in the steel industry: the ArcelorMittal Gent case. Accepted for publication in J. Clean. Prod. DOI 10.1016/j.jclepro.2009.12.016.

[3] L.C. Dreyer, A.L. Niemann, M.Z. Hauschild, Comparison of three different LCIA methods: EDIP97, CML2001 and Eco-indicator 99 - Does it matter which one you choose? Int. J. Life Cycle Ass. 8 (2003) 191-200.

[4] J.C. Bare, T.P Gloria, Critical analysis of the mathematical relationships and comprehensiveness of life cycle impact assessment approaches, Environ. Sci. Technol. 40 (2006) 1104-1113. 
[5] M.A.J. Huijbregts, U. Thissen, J.B. Guinée, T. Jager, D. Kalf, D. van de Meent, A.M.J. Ragas, A. Wegener Sleeswijk, L. Reijnders, Priority assessment of toxic substances in life cycle assessment. Part I: Calculation of toxicity potentials for 181 substances with the nested multi-media fate, exposure and effects model ASUS-LCA, Chemosphere 41(2000) 541-573.

[6] M.A.J. Huijbregts, U. Thissen, T. Jager, D. van de Meent, A.M.J. Ragas, Priority assessment of toxic substances in life cycle assessment. Part II: assessing parameter uncertainty and human variability in the calculation of toxicity potentials, Chemosphere 41(2000) 575-588.

[7] M.A.J. Huijbregts, J.B. Guinée, L. Reijnders, Priority assessment of toxic substances in life cycle assessment. Part III: Export of potential impacts over time and space, Chemosphere 44 (2001) 59-65.

[8] M.A.J. Huijbregts, J. Struijs, M. Goedkoop, R. Heijungs, A. Jan Hendriks, D. van de Meent, Human population intake fractions and environmental fate factors of toxic pollutants in life cycle impact assessment, Chemosphere 61 (2005) 1495-1504. [9] M. Goedkoop, R. Spriensma, The Eco-Indicator 99 - A damage oriented Method for life cycle impact assessment, Pré Consultants, Amersfoort, 2001.

[10] B. Steen, A systematic approach to environmental priority strategies in product development (EPS), Version 2000 - Models and Data of the default system. Chalmers University of Technology, Centre for environmental assessment of products and material systems (CPM) Report 1999 (5), Göteborg, 1999.

[11] M. Hauschild, H. Wenzel, Environmental assessment of products. Volume 2: Scientific background, Chapman and Hall, London, 1998. 
[12] R.K. Rosenbaum, T.M. Bachmann, L. Swirsky Gold, M.A.J. Huijbregts, O. Jolliet , R. Jurastke et al., USEtox-the UNEP-SETAC toxicity model: recommended characterization factors for human toxicity and freshwater ecotoxicity in life cycle impact assessment, Int. J. Life Cycle Ass. 13 (2008) 532-546.

[13] E.G. Hertwich, W.S. Pease, T.E. McKone, Evaluating toxic impact assessment methods: What works best? Environ. Sci. Technol. 32 (1998) 138A-144A.

[14] M. Hauschild, M.A.J. Huijbregts, O. Jolliet, M. Macleod, M. Margni, D. van de Meent, R.K. Rosenbaum, T.E. McKone, Building a model based on scientific consensus for life cycle impact assessment of chemicals: the search for harmony and parsimony, Environ. Sci. Technol. 42 (2008) 7032-7037.

[15] VMM- Vlaamse Milieu Maatschappij, Core set of environmental data MIRA-T 2007, available at www.milieurapport.be

[16] Toxicological Profile for Benzene. Agency of Toxic Substances and Disease Registry (ATSDR), Atlanta, 2007.

[17] Toxicological Profile for Formaldehyde. Agency of Toxic Substances and Disease Registry (ATSDR), Atlanta, 1999.

[18] Toxicological Profile for Toluene. Agency of Toxic Substances and Disease Registry (ATSDR), Atlanta, 2000.

[19] Toxicological Profile for Xylenes. Agency of Toxic Substances and Disease Registry (ATSDR), Atlanta, 1999.

[20] Toxicological Profile for 1,2-dichloroethane. Agency of Toxic Substances and Disease Registry (ATSDR), Atlanta, 2001.

[21] Assessment of The Health Risk of Dioxins: Re-evaluation of The Tolerable Daily Intake (TDI). World Health Organisation (WHO), Geneva, 1998. 
[22] Toxicological Profile for Tetrachloroethylene. Agency of Toxic Substances and Disease Registry (ATSDR), Atlanta, 1997.

[23] Toxicological Profile for Vinylchloride. Agency of Toxic Substances and Disease Registry (ATSDR), Atlanta, 2006.

[24] Environmental Health Criteria 188: Nitrogen Oxides. World Health Organisation (WHO), Geneva, 1997.

[25] Environmental Health Criteria 8: Sulfur Oxides and Suspended Particulate Matter. World Health Organisation (WHO), Geneva, 1979

[26] Toxicological Profile for Arsenic. Agency of Toxic Substances and Disease Registry (ATSDR), Atlanta, 2007.

[27] Toxicological Profile for Beryllium. Agency of Toxic Substances and Disease Registry (ATSDR), Atlanta, 2002.

[28] Toxicological Profile for Cadmium. Agency of Toxic Substances and Disease Registry (ATSDR), Atlanta, 2008.

[29] Toxicological Profile for Chromium. Agency of Toxic Substances and Disease Registry (ATSDR), Atlanta, 2008.

[30] Toxicological Profile for Mercury. Agency of Toxic Substances and Disease Registry (ATSDR), Atlanta, 1999.

[31] Toxicological Profile for Manganese. Agency of Toxic Substances and Disease Registry (ATSDR), Atlanta, 2008.

[32] Toxicological Profile for Nickel. Agency of Toxic Substances and Disease Registry (ATSDR), Atlanta, 2005.

[33] Toxicological Profile for Antimony. Agency of Toxic Substances and Disease Registry (ATSDR), Atlanta, 1992. 
[34] Toxicological Profile for Selenium. Agency of Toxic Substances and Disease Registry (ATSDR), Atlanta, 2003.

[35] Toxicological Profile for Thallium. Agency of Toxic Substances and Disease Registry (ATSDR), Atlanta, 1992.

[36] Toxicological Profile for Vanadium. Agency of Toxic Substances and Disease Registry (ATSDR), Atlanta, 2009.

[37] Toxicological Profile for Zinc. Agency of Toxic Substances and Disease Registry (ATSDR), Atlanta, 2005.

[38] L. Rey-Salgueiro, E. Martínez-Carballo, M.S. García-Facón, J. Simal-Gándara, Effects of a chemical company fire on the occurrence of polycyclic aromatic hydrocarbons in plant foods, Food Chem. 108 (2008) 347-353 